\title{
Application of Rasch to Verify Different Building Competency Sub Constructs for Competency Evaluation of Graduates in Nigeria
}

\author{
Shirka Kassam Jwasshaka, Nor Fadila Moh'd Amin
}

\begin{abstract}
Incessant concerns from employers and private sectors about the incompetence of graduates in Nigeria call for the creation of an assessment tool that could verify their skills. But there is no clear generally accepted and validated assessment instrument available for evaluating graduate performance. The aim of this study was to develop a valid instrument for assessing competency levels of building construction graduates in Nigeria. Survey design was adopted to obtain expert opinions on the validity of the sub-constructs and the related items about the employers 'needs. Three experts from the academic, public, and private sectors subjected the survey instrument to face, content, and construct validity and reliability. The survey instrument, which was analysed using IBM SPSS and WINSTEP version 3.73.3 was answered by a total of 200 building experts selected by proportionate stratified sampling technique. The consistency of the instrument was determined by fit statistics and point measure correlation (PTMEA Corr), for construct validity. The results revealed a very good items and person reliability of 0.97 and 0.94 respectively. Likewise, appropriate PTMEA Corr range from 0.36 to 0.68. Infit and outfit means square range obtained between 0.58 to 1.39. The findings give students, employers and academic institution a realistic and theoretical interpretation of the reality of labour market needs.
\end{abstract}

Keywords: Validation, Assessment, Instrument, Competency

\section{INTRODUCTION}

Scholars has defined the concept competency in diverse ways. In the context of this study competency refers to ability to display proficiency in specific sub constructs. Assessment means the process of planning, Designing and developing, quality check, and collecting evidences to make judgements on whether competency has been achieved, to confirm that an individual can perform to the standard required in the workplace, as specified in a training package [1]. Notably, missing link in most training programme in Nigeria is the absence of a valid assessment instrument that will test the efficiency of individual in these competencies specially to ascertain competency of individuals in specific occupation.

Competency framework for specific job measures individuals who will be effective and competent to perform tasks in that occupation [2]. There is a global campaign on the essential of preparing graduates who are competent, productive, and proactive to carry out tasks in specific competencies in the $21^{\text {st }}$ century.

Revised Manuscript Received on July 10, 2020

* Correspondence Author

Shirka Kassam Jwasshaka*, School of Technical Education, Plateau State Polytechnic, Barkin Ladi Nigeria

Nor Fadila Moh'd Amin, Faculty of Social Sciences, and Humanities, Technical and Engineering Education, University of Technology Malaysia

(C) The Authors. Published by Blue Eyes Intelligence Engineering and Sciences Publication (BEIESP). This is an open access article under the CC BY-NC-ND license (http://creativecommons.org/licenses/by-nc-nd/4.0/)
According to [3] graduates need to be equipped with competency that can be applied in their daily life.

\section{BACKGROUND OF THE STUDY}

In view of the advancement in technology which is gradually changing the trends in the labour market, it is imperative to raise generation of individuals who are competent, think creatively, make critical decision and work independently, and relate positively with individuals. Achieving this depends largely on the quality of assessment instrument to determine the desired competency acquired. Valid assessment instrument stimulates real-life working situation, competencies and knowledge. Assessment tools are used to examine students achievements in one or more domains such as affective, psychomotor, and cognitive, creativity and applications [3]. Psychomotor domain is one of the domain that is still rare to assess. Often regarded as a practice or performance skills which one of them is display of specific skills in building construction could be achieved by demonstration through hands-on exercise in the workshop. The current competency assessment tools used by the concerned stakeholders has proven inefficient owing to inability of building construction graduates to secure a decent job at graduation as a result of lack of specific skills. Consultation with experts in field is critical in ensuring because it will assist in aligning the assessment instrument to current industry methods, technologies, performance and employers expectations [1]. Therefore, easiest way to obtained a widely accepted assessment tool is researcher's consultations with variety of industry stakeholders.

Most of the assessment tools for competency are not validated by experts according to the needs of employers and above all dominated by general knowledge theoretical contents and little emphasis on specific hands-on assessment. [4] revealed that there has been inconsistency in measurement of graduates' competency for employment because of the failure of most existing evaluation instrument to include assessment of employability competency. Additionally, failure to identify dynamism in the labour market related to their particular occupation. Development of an assessment tool with specific constructs and Validated by experts would change the narrative among the stakeholders on how competency assessment of graduates is of paramount importance. [5] observed that Rasch measurement model is significantly the process of sub construct validation, where questionnaire items constitute the instrument designer's empirical definition of the sub construct.

\section{Published By:}




\section{Application of Rasch to Verify Different Building Competency Sub Constructs for Competency Evaluation of}

Graduates in Nigeria

Development of a valid and reliable assessment instrument for determining competency levels of graduates is sacrosanct as labour market becomes dynamic [6]. The standards for educational and psychological testing, which were prepared by the American Educational Research Association, American Psychological Association, and the National Council on Measurement in Education (1999), require that measures be reliable and valid predictors of outcomes. In the light of this proposition, competency of graduates in specific building construction skills could be determined using valid assessment tool for selection or promotion, performance appraisal or any developmental opportunity that may affect pay or career opportunities. Instrument is said to be valid when it is consistent in measuring what is meant to be measured. In other words, it is valid for a particular variable when it accurately measures a prescribed variable.

There are four types of validity, face validity, criterion validity, content validity, or construct validity. Face validity is subset of content validity where experts are asked their opinion about whether an instrument measures the intended competencies [7]. Criterion validity demonstrates the relationship between one measure and other factors, whereas content validity looks at the content of items. Construct validity, measures the extent to which an instrument accurately measures a theoretical construct that was designed to measure. The focus of this study was to ensure face, contents and constructs validity and reliability of instrument for assessing specific competency of graduates of building construction. In assessing validity of research instrument, three main criteria often considered are face validity, content validity, and construct validity [7].

Validity and reliability are closely related, instrument can be reliable but not valid, however, it is valid because is reliable. Therefore, a valid instrument must be reliable. According to [8] is difficult checking for instrument validity than reliability because validity concerns measurement of constructs related to knowledge whereas reliability concerns determination of consistency of scores.

Rasch measurement model is a psychometric technique capable of improving the precision of research constructs and sub-constructs, instruments, monitor instrument quality, and compute respondents' performances. It provides a technique for obtaining insight into how the data cooperate with constructs measures [9] and for converting raw observational data into item difficulty and person ability estimated on an approximately linear scale. [11] developed a rating scale instrument quality criteria to serve as a rule of thumb for decision making based on his many years of experience and available literature in conducting Rasch analysis in diverse ways. Table 1 show a rating scale instrument rule of thumb for making decision.

Table 1 Rating Scale Instrument Rule of Thumb

\begin{tabular}{llllll}
\hline $\begin{array}{l}\text { Criterion } \\
\text { Targeting }\end{array}$ & $\begin{array}{l}\text { Poor } \\
>\mathbf{2}\end{array}$ & $\begin{array}{l}\text { Fair } \\
\mathbf{1 - 2} \text { errors }\end{array}$ & $\begin{array}{l}\text { Good } \\
<\mathbf{1} \text { error }\end{array}$ & $\begin{array}{l}\text { Very Good } \\
<.5 \text { error }\end{array}$ & $\begin{array}{l}\text { Excellent } \\
<.25 \\
\text { error }\end{array}$ \\
\hline Item model fit Mean Square Range & $<.3->3.0$ & $0.34-2.9$ & $0.5-2.0$ & $0.71-1.4$ & $0.77-1.3$ \\
& & & & & \\
& $<0.67$ & $0.67-.80$ & $0.8-0.90$ & $0.91-0.94$ & $>0.94$ \\
Person and Item Measurement Reliability & 2 or less & $2-3$ & $3-4$ & $4-5$ & $>5$ \\
Person and Item Separation & $>5 \%$ & $2-5 \%$ & $1-2 \%$ & $0.5-1 \%$ & $<0.5 \%$ \\
Ceiling Effect: \% Maximum extreme Scores & $>5 \%$ & $2-5 \%$ & $1-2 \%$ & $0.5-1 \%$ & $<0.5 \%$ \\
$\begin{array}{l}\text { Floor effect: \%Minimum extreme } \\
\text { Variance in data explained by measure }\end{array}$ & $<50 \%$ & $50-60 \%$ & $60-70 \%$ & $70-80 \%$ & $>80 \%$ \\
$\begin{array}{l}\text { Unexplained variance in contrasts 1-5 of PCA } \\
\text { of residuals }\end{array}$ & $>15 \%$ & $10-15 \%$ & $5-10 \%$ & $3-5 \%$ & $<3 \%$
\end{tabular}

\section{Source; Fisher (2018)}

\section{LITERATURE REVIEW}

[10] carried a study to examine the validity and reliability of competency assessment instrument among building Surveyor graduates using Rasch measurement model and the result of their findings showed a very good items and person reliability index. With high level of consistency in measuring the graduates' competency domains it was concluded that the instrument was reliable and acceptable. In a study to determine the implementation of performance assessment for measuring junior high school students' science process skills in excretion system, the results revealed that the assessment instrument was valid in substance, construction, language aspect [3]. [6] conducted a study aimed at developing a reliable and valid approach to assessing sustainable competencies among secondary school students. The findings of their study indicated that the assessment tool was suitable to measure competency sustainability.

[7] observed in their study to outline a systematic procedure to develop a valid competency model and instrument to measure competency of Chefs who works in the hotel industries in Malaysia that to maintain accuracy of questionnaire from defect, validity and reliability of the instrument is very essential. the skills challenges facing graduates of building construction in Nigeria today calls for improvement validation of training programmes. Nigeria construction industry need graduates who can work intelligently, and flexibly, and who can meet the demand of the labour market to contribute to economic, social, cultural, technical, and labour force environmental changes. The Nigerian construction industry requires graduates who have the hands-on skills and knowledge to function effectively in their designated roles [8]. [9] in their study to develop performance indicators and their related priority weightings for evaluating staff or competency in Waste Management Company, the results of their study revealed that evaluation of staff competencies consist of 3 dimensions and 11 criteria, competencies in order of importance were Attitude, Knowledge, and Skills.

Published By:

Blue Eyes Intelligence Engineering

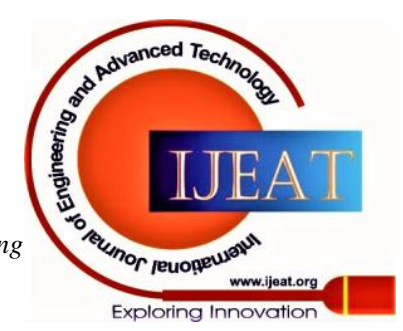




\section{METHOD}

The study employed quantitative research approach using survey design with 16 specific building construction constructs and sub-constructs were identified from literatures such [13]; [16]; [10] and Residential Construction Industry Competency Model,(n.d.). to ensure the validity and reliability and wider acceptance of the instrument, the constructs and the items were validated by experienced experts for face and content validity. The input of the validators was used to revise and refine the items.

Fit statistics of the instrument was analysed to ensure the Infit and outfit, and Point Measure Correlation (PTMEA Corr) is within the threshold by [12]. During this process, Infit and out range from 0.4 to 1.5 logit were considered acceptable according to rating scale threshold for Rasch measurement model [13];[14], and [11]. Only positive values PTmea Corr. Range between 0.4 to 0.8 were accepted, but negative point measure value with standard deviation from 1.40 to -0.87 can be considered [14]. The constructs and items retained and used for validation of this competency assessment instrument after experts' verification is as shown in Table 2. Closed-ended 5-point Likert scales format was used for the survey instrument where respondents were allowing to choose from the items on the bases of importance ranging from 1 (not important), 2 (Less Important) 3 (somewhat Important), 4 (Important), and 5 (Most Important). Furthermore, a total of 200 experienced building construction experts selected through stratified random sampling techniques participated in the study. Again, in processing the information data for this research, the statistical analysis procedure was applied with the assistance of the Rasch measurement model using a Winstep software version 3.73.3.

\section{A.Reliability and separation}

The reliability and the separation index of this instrument was according to rating scale criteria by Fisher table of rule of thumb for rating scale in table 1 above. Similarly, [14] mentioned that for the Cronbach's Alpha reliability coefficient, the value range from 0.0 to 1.0 which denotes that the closer the value to 1 , the more reliable the instrument. In addition, the person separation value range from 3 to $>5$ indicates how well the test is successful in identifying differences in each person's competency, while items separation indicates how well and reproduce able the items are to produce a consistent result when administered on subject with same characteristics [15]: [14].

\section{RESULTS/DISCUSSION}

The results for the study is presented into three major phases, in first phase, to ensure face validity and reliability of the specific competency constructs and sub-constructs, three experienced experts were engaged to refine the instrument based on the need of the employers. There after the refined instrument was administered on a larger sampled population of experts in the field to ensure wider acceptability. After rigorous scrutiny by experts, total of 16 specific building construction sub-constructs with 82 items were okayed, see details in table 6 . The sub-constructs are shown in Table 2 below.

Table 2 Sub constructs and elements of specific building construction competency

\begin{tabular}{lcc}
\hline \multicolumn{1}{c}{ Competency sub constructs } & Items & Code \\
\hline Plumbing & 5 & TP \\
Tiling & 5 & TT \\
Carpentry and Joinery & 6 & TCJ \\
Block/brick laying & 5 & TBB \\
Concreting & 4 & TCC \\
Blueprint/Design interpretation & 5 & TD \\
Roofing & 7 & TRF \\
Scaffolding & 5 & TSC \\
Site Preparation & 6 & TSP \\
Setting out & 7 & TSO \\
Estimation and Scheduling & 7 & TES \\
Maintenance and repairs & 6 & TM \\
Painting and decoration & 5 & TPD \\
Plastering & 5 & TPL \\
Iron Bending & 4 & TIB \\
General Technical Knowledge & 6 & TGK \\
\hline Total & $\mathbf{8 2}$ &
\end{tabular}

For content validity and reliability, the entire survey instrument was analysed using Rasch measurement model. The output from summary of statistics was interpreted following the instrument quality criteria set for rating scale by [11] as presented in table 1 above. Item separation and reliability show a very good and excellent values of 4.05 and 0.94 respectively, which is an indication that the items were consistent and reproducible when administered to same sample with same characteristics. The high item reliability indicates that the is reproducible to measure what is supposed to measure. Similarly, person separation and reliability show how well the test identifies differences in person's abilities with person's separation of 5.48 and reliability of 0.97 .

The entire instrument revealed a consistent and reliable results to measure competency effectively considering the high Cronbach Alpha of 0.98. [14] mentioned that for the Cronbach's Alpha reliability coefficient, the value range from 0.0 to 1.0 which denotes that the closer the value to 1 , the more reliable the instrument.

Published By:

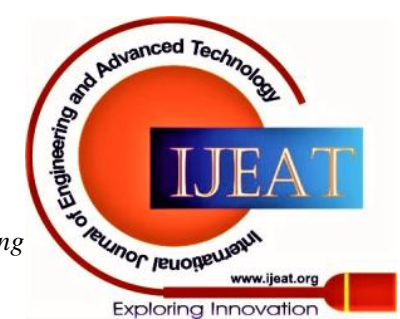


In addition, the person separation value range from 3 to $>5$ indicates how well the test is successful in identifying differences in each person's competency, while items separation indicates how well and reproduce able the items are to produce a consistent result when administered on subject with same characteristics. The inference drawn from the result is that the competency assessment instrument is appropriate and effective to measure competency of graduates in specific building construction skills. See Table 3 below.

Table 3. Reliability and separation

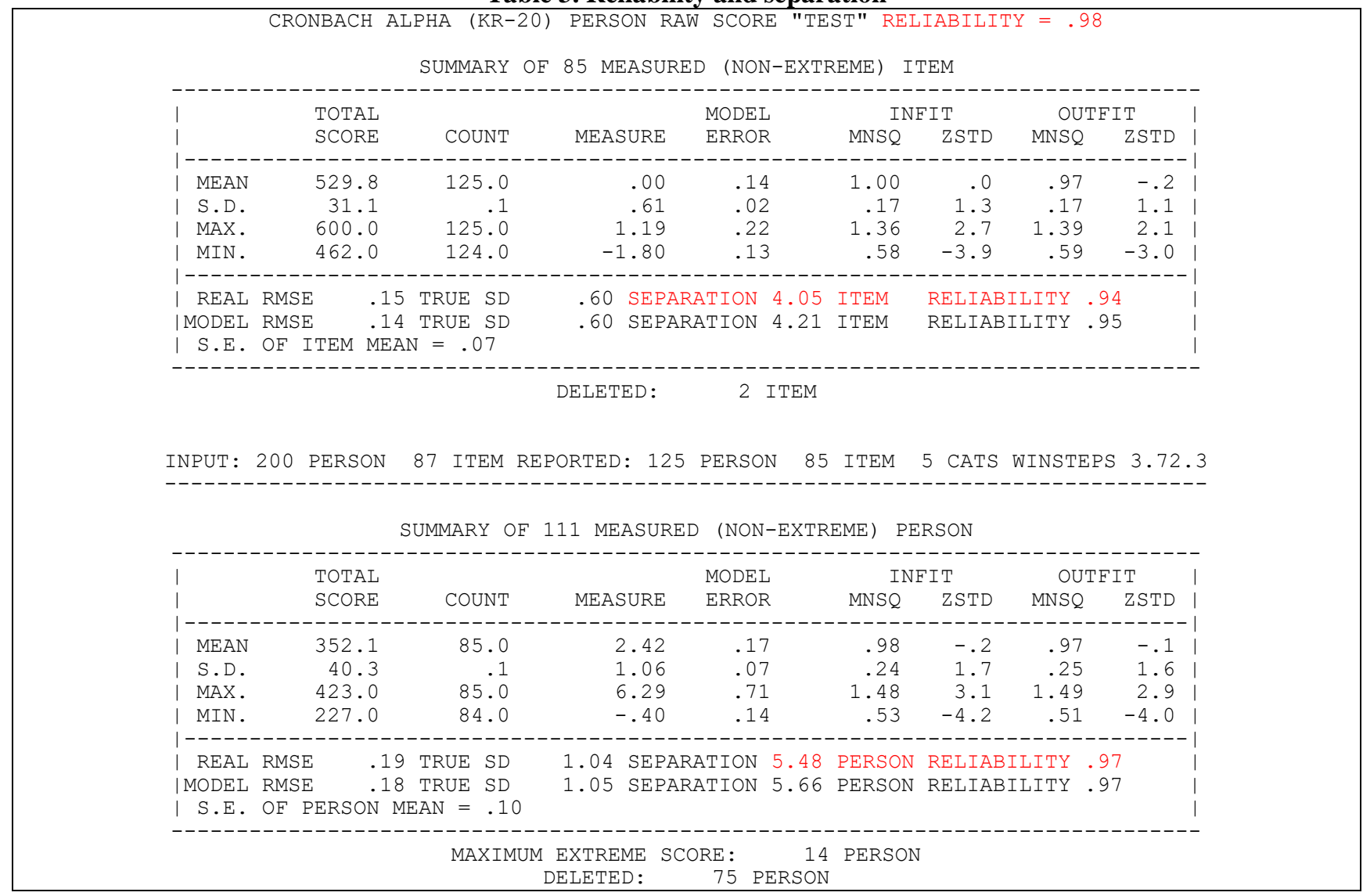

The third phase of the study focused on determining construct validity of the instrument. To achieve this Point Measure Correlation (PTMea Corr), fit statistics where Infit and Outfit mean square (MNSQ) and Z-standard (ZSTD) was considered. In a similar manner rating scale table of criteria in table 1 above was referred to. The entire items were screened to ensure that only items with positive values of Point measure correlation were considered valid. According to [16] in determining PTMEA Corr. all items need to align in the same direction with positive correlation. The author added that negative PTMea indicate a contradictory response between items and person response as it relates to the sub constructs developed. According to [17] PTMea Corr. Values between 0.20 and 0.79 is accepted and any item with a negative (-) value and below 0.20 must be rejected because the item indicates not to measure any construct.

Table 4 Rule of thumb for Fit statistics

\begin{tabular}{|c|c|c|}
\hline \multirow{2}{*}{$\begin{array}{c}\text { Criterion } \\
\text { PTMEA Corr }\end{array}$} & \multirow{2}{*}{$\begin{array}{l}\text { Acceptable for Rating Scale } \\
0.2<\text { PTMear Corr. }<0.79\end{array}$} & $\begin{array}{ll} & \text { Sources } \\
\end{array}$ \\
\hline & & {$[17]$} \\
\hline & $0.4<$ PTMea Corr. Value $<0.80$ & [14]; \\
\hline Outfit MNSQ & $0.5<$ MNSQ value $<1.5$ & [13] \\
\hline & $0.6<$ MNSQ value $<1.4$ & [18] \\
\hline Outfit ZSTD & $-2.0<$ ZSTD value $<+2.0$ & [19] \\
\hline
\end{tabular}

The survey instrument was treated for fit statistics until there was no any item with negative (-ve) PTMea Corr. The results of the fit statistics in table 5 below show that the items retained met the index of PTMea Corr. By John Linacre in the table 4 above with PTMea index range between 0.36 to 0.68 . additionally, the items for treated for Infit and Outfit MNSQ to detect and remove any misfit item. Any item with Infit value outside the range of 0.5 to 1.5 were removed because they fall short of meeting the specified index by [13] and
[18]. When the Infit and Oufit MNSQ are accepted then the ZSTD value can be overlooked [19] and [15]. Consequently, the result show that the items possess good construct validity with Infit and Oufit index between 0.58 to 1.39 , therefore the extreme ZSTD were ignored. Table 5 show the details statistics of fit statistics for the specific items that made up the assessment instrument.

Published By:

Blue Eyes Intelligence Engineering

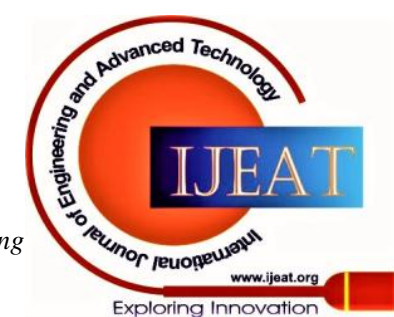


Table 5 Items statistics

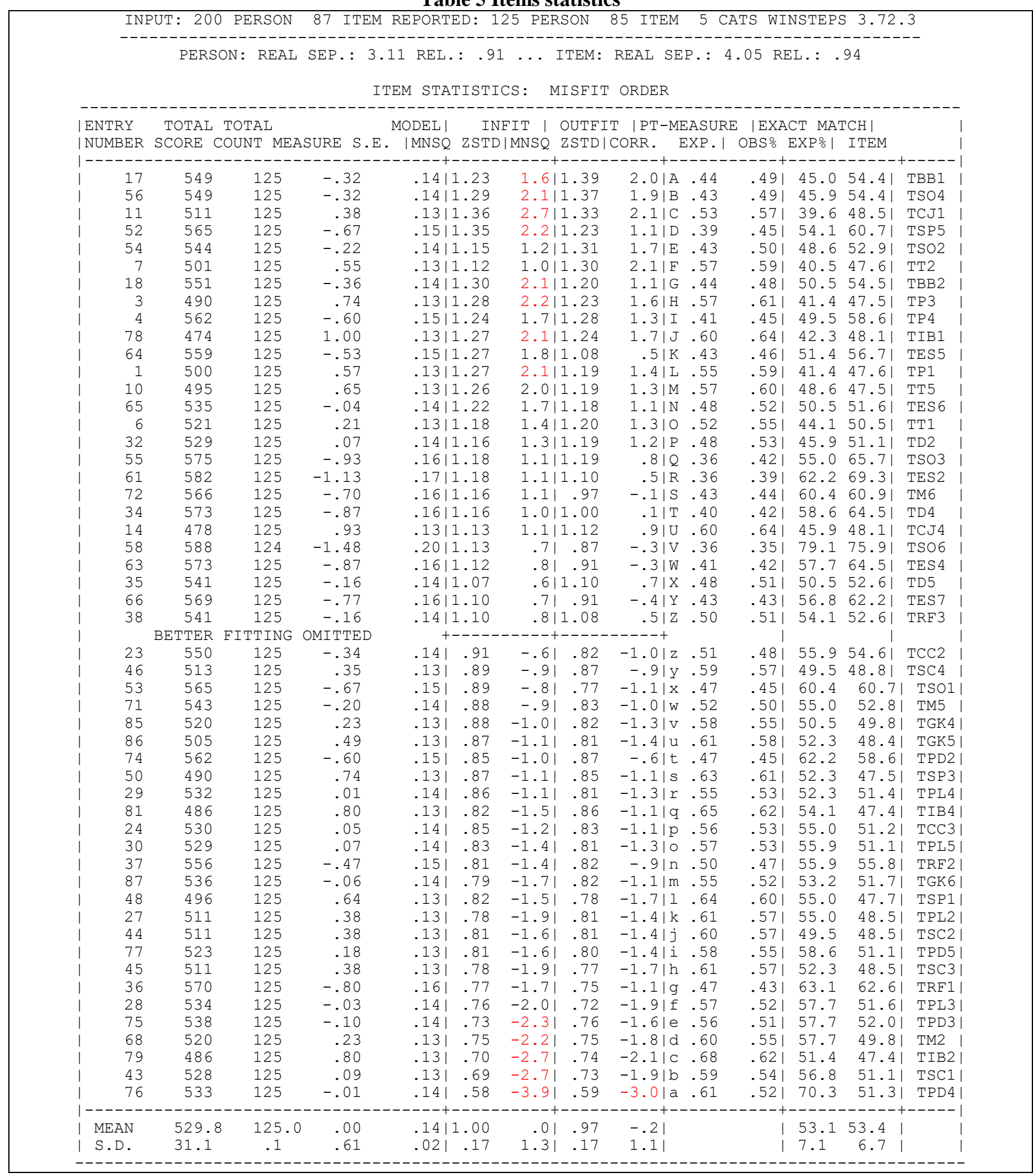

Therefore, it could be inferred that the entire items entered and analyzed using Rasch analysis met the specified criteria for rating scale. Thus, is capable of assessing specific building construction competency of graduates to produce valid result. From the rigorous process of screening, refining, and subjecting the instrument to experts' validation and reliability to obtain on the spot information concerning specific competency relating to building construction, the researchers develop the instrument for assessing

graduate's competency as shown in Table 6 below. The assessors are required to rate the graduates in terms of their competency in items under each competency sub construct. 
Table 6 Competency Assessment Instrument

\begin{tabular}{l} 
TP1 Plumbing \\
Expected competencies \\
\hline 1. \\
2. Ability to assemble repair toilet appliances \\
3. Ability to fit pipes in plumbing work \\
4. Ability to use various Plumbing tools and equipment correctly \\
5. Ability to interpret working drawings \\
\hline
\end{tabular}

\section{TT 2. Tiling Skills}

Ability to identify tile types and sizes

Skills in application of floor tiles

Skills in application of wall tiles/skirting

Skills in cutting tiles for specific purposes

5. skills in laying tiles with minimal wastage/breakage

\section{TCJ3. Carpentry/Joinery Skills}

1. Skills in basic Carpentry and Joinery

2. Ability to Identify wood (texture, figure of wood)

3. Ability to use simple joinery tools and equipment

4. $\quad$ Ability to Fix iron mongery in doors and windows

5. Skills in construction and dismantling of formwork

6. Ability to fix wooden doors and windows/frame

TBB4. Bricklaying and Block laying Skills

Skills in forming first course of block work

Skills in aligning blocks in straight-line

Skills in the use of simple building tools and equipment

Skills in applying mortar bed for block work

Skills in maintaining alternate mortar joint in block work

\section{TCC5. Concreting Skills}

1 Ability to identify appropriate mix ratio for specific jobs

2 Ability to identify quality of concreting materials

3 Skills in placing concrete in a formwork

$4 \quad$ Skills in curing concrete components

\section{TPL6. Plastering Skills}

Skills in application of mortar to wall

Skills in displaying dexterity in dressing walls and windows

Ability to select good plastering sand

Skills in maintaining mixed ratios in plastering operation

Skills in maintaining uniform thickness during plastering

\section{TD7. Blueprint/Drawing/Specifications}

Skills to draw rough /detailed scale plans for building structure

Skills in production of prototype of a building structure

Ability to recognize elements and symbols of blueprints

$4 \quad$ Ability to Interpret dimensions, types of lines, and scales

Ability to locate worksite features on a construction plan

\section{TRF8. Roofing Skills}

1 Skills in forming roof trusses on wall

Ability to interpret roof design details

Skills in identifying various roofing members

Ability to Identify various roof covering sheets

Skills in laying modern roofing sheets

Skills in proper spacing of roof members

Ability to Identify roofing sheets connectors

\section{TSC9. Scaffolding Skills}

1 Ability to identify parts of scaffold

Skills in Assembling tubular scaffold

Skills in Assembling bamboo scaffold

Skills in Construction of wooden scaffold

Skills in dismantling of tubular scaffold

\section{TSP10. Site Preparation Skills}

Skills in providing free access to new site

Ability to identify nature of construction site soil

Skills in using site preparation tools and equipment

Competent

\section{Checklist Scores}

Not Competent $\mathbf{0}$ 
4 to identify building line, setback, corners, and elevation

5 Ability to Prepare site for excavation

6 Ability to Lay foundations

TSO11. Setting out Skills

$1 \quad$ Skills interpret building design details

2 Skills in transmitting correct building dimensions to the ground

3 to identify foundation trench /wall thickness on profile boards

$4 \quad$ Skills in setting out using 3:4:5 method

$5 \quad$ Skills in Setting out using simple levelling instrument

6 Ability to use simple setting out tools and equipment

$7 \quad$ Skills in positioning profile boards/pegs

TES12. Estimating and Scheduling Skills

$1 \quad$ Skills in marketing during purchase of building materials

2 Ability to Identify quality materials for specific jobs

3 Skills in proper estimation of construction materials

$4 \quad$ Skills in smooth delegating of tasks on site

$5 \quad$ Skills in scheduling of site daily job

$6 \quad$ Skills in time management for productivity

$7 \quad$ Skills in critical analysis of costs of construction materials

\section{TM13. Building Maintenance/Repairs}

Ability to identify fault in construction

Skills in proffering solution to construction defects

Ability to use appropriate materials to address faults

Skills in preventative maintenance to service structures

Skills to repair and restore existing structures

Dexterity in maintenance of building tools and equipment

\section{TPD14. Painting and decoration Skills}

$1 \quad$ Skills in mixing paint

Skills in preparing wall surface for painting

Skills to apply paints to wall surface to admiration of clients

Skills in the use of painting and decoration tools

Ability to Identify primary and secondary colours in paints

TIB15. Iron Bending Skills

1 Ability to Identify Iron rod sizes for specific purpose

Skills in bending iron bars of different sizes

Skills in bending rods according to measurements

Skills in bending irons bars for different concrete components

\section{TGK16. General Technical Knowledge}

1 Knowledge of contemporary technological issues

2 Knowledge of professional ethics

3 Knowledge of Building codes

4 Knowledge of appropriate roof and drainage gradient

$5 \quad$ Knowledge of parts of scaffolds

$6 \quad$ Knowledge of properties of building materials

\section{Total Score}

\section{IMPLICATIONS}

Convincing theoretical and practical implications emerged from the findings of this study because relevant major stakeholders in building construction industry were carefully selected. The experts gave first-hand information about the current practices and their experiences with fresh graduates in the field and during employment interview. The findings have enormous theoretical and practical implications for graduates, Educational Institutions, Government, Private and Public employers of labour, Professional bodies, and Researchers. Theoretical implications to the Institutions is that they will strive to disseminate more specific knowledge rather than the general knowledge hitherto provided to graduates. The findings will make instructors to create workplace environments in the classroom; hence, bringing hands-on training to the academic setting. The findings will serve as document for introducing internship programme for other graduates who desire to update their competency. Policy makers could use the framework to improve the existing Nigeria Skill Qualification Framework (NSQF) to meet the

current realities. The findings will add value to the body of knowledge by contributing to the empirical literature concerning competencies in the workplace. Practical implication to private and public sector employers is that they can use the instrument as a template for training and re-training of staff in competency for career advancement. Professional bodies can also use the framework as a reference document for professional selection of fresh graduates into the profession. Organisations can use the instrument as documented evidence for interview selection of fresh graduates for employment. Finally, it contributes to the body of knowledge as it can be used for inculcating specific competencies required by employers in students for effective transition to work environment.

Published By:

Blue Eyes Intelligence Engineering and Sciences Publication

(C) Copyright: All rights reserved.

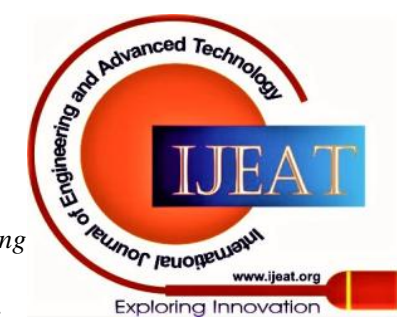




\section{Application of Rasch to Verify Different Building Competency Sub Constructs for Competency Evaluation of Graduates in Nigeria}

\section{CONCLUSIONS}

Employers are highly concerned about the quality of graduates provided by educational institutions due to the lack of skills to fulfil their requirements. Higher institutions were unable to fulfil their policy mandate because the curriculum concentrated more on theory than realistic, and did not have adequate coordination for competence training between the institutions and the industries. In the course of this study, contact with experts and labour employers revealed that graduates lack sufficient skills in their various careers chosen to meet employers 'demands. Different literatures were united in their belief that the job market today needs graduates with both technical and non-technical skills to be employed and effectively employed. A comprehensive and meticulous analysis processes and methods were followed to ensure comprehensibility, dependability, and validity of the instrument to improve the system.

\section{ACKNOWLEDGEMENT}

The authors wish to express their gratitude to all scholars whose works were made accessible for reference purpose to add value to the body of knowledge. We sincerely say thank you to the management of Universiti Teknologi, Malaysia for their support in providing the enabling environment for academic activities to strive towards meeting the global standard. A big thank you to my co-authors whose contributions made this for a huge success. More grease to your elbows.

\section{REFERENCES}

1. Hodge RA, Hardi P, Bell DVJ, Australian Skills Quality Authority, Sebhatu SP, Schröter D, et al. Guide to developing assessment tools. Aust Ski Qual Auth [Internet]. 2015;(August):1-11. Available from: http://www.asqa.gov.au/verve/_resources/Guide_to_developing_asses sment_tools.pdf\#search=guide to developing assessment tools

2. Suhairom N, Musta'amal AH, Amin NFM, Johari NKA. The Development of Competency Model and Instrument for Competency Measurement: The Research Methods [Internet]. Vol. 152, Procedia Social and Behavioral Sciences. Elsevier B.V.; 2014. p. 1300-8. Available from: http://linkinghub.elsevier.com/retrieve/pii/S1877042814054342

3. Ramadani M, Supahar S, Rosana D. Validity of evaluation instrument on the implementation of performance assessment to measure science process skills. J Inov Pendidik IPA. 2017;3(2):180.

4. Ryan G, Spencer LM, Bernhard U. Development and validation of a customized competency-based questionnaire: Linking social, emotional, and cognitive competencies to business unit profitability. Cross Cult Manag. 2012;19(1):90-103.

5. Heale R, Twycross A. Validity and reliability in quantitative studies. Evid Based Nurs. 2015;18(3):66-7.

6. Waltner EM, Rieß W, Mischo C. Development and validation of an instrument for measuring student sustainability competencies. Sustain. 2019;11(6):1-20.

7. Rahayah Ariffin S, Omar B, Isa A, Sharif S. Validity and reliability Multiple Intelligent item using Rasch measurement model [Internet]. Vol. 9, Procedia - Social and Behavioral Sciences. 2010. p. 729-33. Available from: http://dx.doi.org/10.1016/j.sbspro.2010.12.225

8. Aigbavboa C, Aliu J. Requisite Skills for Graduate Success: Perceptions of the Nigerian Construction Industry. Vol. 6, Socioeconomica. 2017. p. 21-42.

9. Wang $\mathrm{CH}$, Liu SH, Pang CT. A study of the evaluation of the staff competencies in waste management company by FAHP. Ekoloji. 2019;28(107):1901-5.

10. Wiseman J, Roe P, Parry E. Skills and Training in the Construction Industry 2014. 2014. p. 145.

11. Residential Construction Industry Competency Model.

12. Fisher WP, Elbaum B, Coulter A. Reliability, precision, and measurement in the context of data from ability tests, surveys, and assessments. Vol. 238, Journal of Physics: Conference Series. 2010.
13. Wright BD. R_Rasch Factor Analysis vs Traditional FA.pdf. 1994.

14. Mutalib AA, Baharom S, Hamzah N. Rasch model analysis of implementation effectiveness for final year research project course in civil \& structural engineering. 2015. p. 11-22.

15. Rashidi M, Begum R, Mokhtar M, Pereira J. The Applications of Rasch Measurement Model for Calibrating Survey Instrument for Analysing the Criteria of Sustainable Construction. Curr World Environ. 2014;9(3):653-62.

16. Linacre M. Winsteps Tutorial 2. Winstep Tutorial. 2012. p. 1-38.

17. Linacre JM. FACET.

18. Azrilah Abdul Aziz, Muhammad Shahar Jusoh, Omar AR, Mohd Haris Amlus, Tuan Salwani Awang. Construct Validity: A Rasch Measurement Model Approaches. Vol. 9, Journal of Applied Science and Agriculture. 2014. p. 7-12.

19. Linacre JM. Winsteps Help for Rasch Analysis 4.4.7. 2019.

\section{AUTHORS PROFILE}

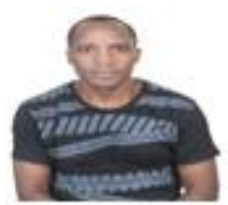

Shirka Kassam Jwasshaka a Senior Lecturer of Plateau State Polytechnic Nigeria graduated from Federal University of Technology, Minna with Bachelors of Technology Education specializing in Building Technology. In his quest for more knowledge he attended one of the prestigious Institution; University of Nigeria Nsukka, where he backed Master's Degree in Industrial Technical Education. He is currently a $\mathrm{PhD}$ scholar at the University of Technology, Malaysia. He is an author of many Journals both local and International.

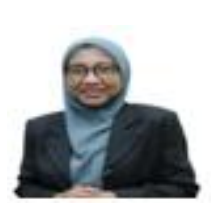

Nor Fadila Mohd. Amin [ PhD] is Senior Lecturer, Season Administrator, facilitator, and a mobilizer at the Universiti Teknologi, Malaysia Department of Technical and Engineering Education. She has authored and Co-authored many books and in reputable Journals both local and international. She is a member of many professional bodies within her occupational call. Her excellent performance in service has earned her different awards both local and international.

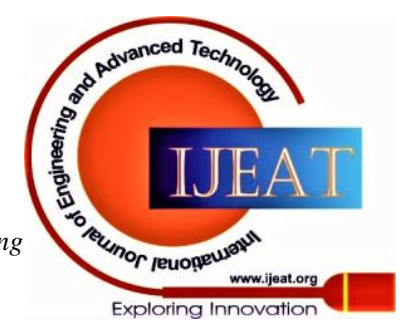

